\title{
A critical look at "Energy savings, emissions reductions, and health co-benefits of the green building movement"
}

\author{
John H. Scofield ${ }^{1}$ - Jakob Cornell ${ }^{1}$
}

Received: 17 March 2018 / Revised: 22 August 2018 / Accepted: 5 September 2018 / Published online: 3 October 2018

(c) Springer Nature America, Inc. 2018

\begin{abstract}
MacNaughton et al. recently published an article entitled, "Energy savings, emissions reductions, and health co-benefits of the green building movement" in which they claim to calculate the environmental co-benefits associated with the (assumed) reduced energy use of green buildings. They consider only LEED (Leadership in Energy and Environmental Design) commercial buildings and make two fundamental assumptions: (1) that each LEED building, year after year, achieves the energy savings projected by its design team, and (2) that the fuel mix of LEED buildings is the same as the average mix for other buildings in the same geographic region.
\end{abstract}

Here we show that these assumptions are not supported by data. Numerous studies have shown that buildings, on average, use significantly more energy than projected by design simulations. Furthermore, a decade of research suggests that LEEDcertified buildings, on average, achieve little or no primary energy savings relative to other similar buildings. In addition, evidence suggests that any reduction in site energy is typically achieved through increased electric use and corresponding off-site energy loss. The environmental benefits of LEED buildings calculated by MacNaughton et al. have dubious value because they are based on assumptions that are inconsistent with measured LEED building energy performance.

\section{Introduction}

In a recent paper "Energy savings, emission reductions, and health co-benefits of the green building movement," MacNaughton, Cao, Buonocore, Cedeno-Laurant, Spengler, Bernstein, and Allen demonstrate the power of Harvard's Co-BE (Co-Benefits of the Built Environment) Calculator by using it to estimate the cumulative environmental cobenefits associated with the (assumed) reduced energy use of nearly 20,000 commercial buildings that were certified under the U.S. Green Building Council's (USGBC) Leadership in Energy and Environmental Design (LEED) program from 2000 to 2016 [1]. The calculation is predicated on the assumption that, following certification, LEED buildings use less energy than do other similar buildings

John H. Scofield

john.scofield@oberlin.edu

1 Department of Physics \& Astronomy, Oberlin College, Wright Laboratory of Physics, 110 N. Professor Street, Oberlin, OH 44074, USA and that the annual energy savings for each LEED building may be extracted from the number of points awarded to it for energy efficiency during the LEED certification process -in most cases, based on design projections rather than actual, measured energy performance.

These assumptions are highly flawed. Numerous studies have found that buildings use more energy than projected by their design teams - the well-documented building "energy performance gap" [2-16]. Moreover, a decade of LEED building studies have either concluded or have yielded results consistent with the conclusion that the source energy consumed by LEED-certified buildings, on average, is not significantly lower than that for other buildings, [16-27]. In short, the methodology demonstrated by the Harvard group is interesting but their conclusions lack validity because they are based on seriously flawed assumptions.

\section{Building site, source energy, and EUI}

Before taking up a detailed criticism of the Harvard group's methodology it is important to precisely define what is meant by "building energy." 
There are two common definitions for building energy in the U.S., one being site energy and the other being source energy (or primary energy).

Site energy is the annual purchased energy used within a building's boundary. Annual site energy is calculated by summing all fuel purchases (electricity, natural gas, district heat, etc) for 12 consecutive months, after first converting each to a common energy unit, Joules $(\mathrm{J})$ in most of the world or British thermal units (Btu) in the U.S. In most cases the phrase "building energy" refers to building site energy.

Since larger buildings use more energy than smaller buildings it is common to divide a building's annual site energy by its gross floor area to obtain the building's site Energy Use Index or Energy Use Intensity (EUI). Site EUI are expressed in $\mathrm{J} / \mathrm{m}^{2}$ or, in the U.S., Btu/ $/ \mathrm{ft}^{2}$.

Site energy and site EUI, however, do not account for energy losses outside the building boundary associated with producing fuels and transporting them to the building. These off-site energy losses may not be of interest to the building owner but they are very important when looking at energy policy, total resource consumption, energy costs, and the environmental impact of a building. These off-site losses occur for all fuels but they are especially important for electric energy which is typically generated from combustion processes (e.g., Rankine and Brayton cycles for steam and gas turbines, respectively) at power plants which operate with $30-40 \%$ efficiency. The total (on- and off-site) primary energy consumed in delivering $1 \mathrm{MJ}$ of electric energy to a U.S. building averages about $3 \mathrm{MJ}$.

Primary energy refers to energy that can be harvestedsolar, wind, nuclear, coal, hydro-power, natural gas, etc. Secondary forms of energy, such as electricity, cannot be harvested but are instead produced from primary sources of energy. The U.S. Environmental Protection Agency has defined building source energy to account for all the primary energy that is consumed in the operation of a building, both on- and off-site [28]. The annual source energy of an all-electric building is roughly three times its site energy. ${ }^{1}$ Annual source EUI, similar to site EUI, is obtained by dividing a building's annual source energy by its gross floor area. On average, source energy provides a much better indication of the total energy and environmental impact of a building than site energy.

\section{The Harvard group's methodology}

The Harvard group calculates the environmental co-benefits associated with the assumed reduced energy use of all

\footnotetext{
1 This ratio is slowly going down in the U.S. as power plants become more efficient and more renewable electric generation is introduced to the grid.
}

commercial LEED-certified buildings certified in six countries (United States, China, India, Brazil, Hungary, and Germany) from 2000 to 2016, estimated to have a total building floor area of 335 million $\mathrm{m}^{2}$ [1]. Our own query to the USGBC LEED project database [29] to retrieve all nonconfidential, commercial projects achieving LEED certification from 2000 to 2016 in these six countries in LEED systems that address whole building energy returns 19714 projects with a total floor area of 333 million $\mathrm{m}^{2}{ }^{2}$ It should be noted, however, that, any building certified more than once (as is often the case in major U.S. cities) gets counted more than once in this sum-so that the numbers are inflated. ${ }^{3}$ The LEED project database lists an additional 3073 confidential projects with a total floor area of 49.5 million $\mathrm{m}^{2}$ that otherwise meet the above criteria. They do not say but we assume that the Harvard group neither eliminates duplicate buildings nor includes confidential buildings in their analysis.

Here we provide a summary of the Harvard group's methodology as best we understand it as it applies to U.S. buildings-which represent the vast majority of the buildings in this study. The Harvard group does not provide a detailed description of their methodology for determining the energy efficiency for each LEED-certified building. They state that this information is obtained from the Green Building Information Gateway (GBIG) web site [30]. The GBIG web site publishes LEED scorecard information for many LEED-certified buildings, including the LEED system and version used for certification, building location, and the number of points earned towards LEED certification, broken out by category including Energy and Atmosphere (EA). The details vary with each LEED system (NC, CS, EBOM, Schools, etc.) and version (v1, v2.0, v2009, v4, etc). For some LEED systems and versions, points earned in the Energy and Atmosphere category 1 (EAc1) can be directly related to the ratio of the projected site EUI for the building design divided by the projected site EUI for a baseline building — as calculated by the building's design team. This energy efficiency ratio, combined with the building's floor area and either the numerator (design EUI) or denominator (baseline EUI), allows one to calculate the projected site energy savings for the building, that is, the difference between the annual site energy projected for a conventional building and the annual site energy projected for this building.

The USGBC does not publicize the projected site EUI for each LEED building so that the numerator of the projected energy efficiency ratio is not accessible. The Harvard

\footnotetext{
${ }^{2}$ LEED systems included are those listed in the earlier footnote 1.

${ }^{3}$ In our queries to the LEED project database we have not developed a methodology to eliminate duplicate buildings short of doing this by hand.
} 
group, instead, estimates the denominator (the baseline EUI), using national and international building energy survey data to determine the gross site EUI and fuel mix used by conventional buildings in the same geographical region as each LEED-certified building. For U.S. buildings they use data from the Energy Information Agency's Commercial Buildings Energy Consumption Survey (CBECS) [31]. ${ }^{4}$ CBECS survey data from three different snapshots in time $(1998,2003$, and 2012) are used to estimate the fuel intensities (electricity, natural gas, fuel oil, district heat) used by conventional buildings. Annual fuel intensities for intermediate years are obtained by interpolation. CBECS data are broken out by nine census divisions (i.e., geographical regions). These data are then used to calculate, for each U. S. LEED-certified building, the individual fuels (electric, natural gas, etc.) used for a baseline building of the same size and census division for each year following the date of certification.

The Harvard group does not differentiate on space type (e.g., office vs hospital) but, instead, uses regionally dependent gross fuel intensities for each building in the same census division, combining these with floor area to yield estimated fuel usage and savings. They assume that the fuel mix for the LEED building is the same as that for the baseline building. Hence a projected $30 \%$ reduction in site energy for the LEED building is translated into a $30 \%$ savings in electric energy, $30 \%$ savings in natural gas, etc. relative to the gross fuel intensities for buildings in that census division determined by CBECS.

The Harvard group notes that the GBIG web site does not post LEED scorecards for buildings certified before 2007. For these buildings they make the simplifying assumption that each building, for every year following certification, has a site EUI of $69 \mathrm{kBtu} / \mathrm{ft}^{2}\left(785 \mathrm{MJ} / \mathrm{m}^{2}\right)$, which corresponds to the median found in one 2008 study of 121 LEED-certified buildings [16]. With this assumption fuel savings relative to baseline are calculated for these buildings as described above.

\section{Flaws in the Harvard methodology}

About 16000 of the 20000 LEED-certified projects considered were certified under New Construction (NC), Core \& Shell (CS), School, or Retail LEED systems and account for $56 \%$ of the 335 million $\mathrm{m}^{2}$ of floor area in this study. For these LEED systems energy efficiency indices EAc1 were based entirely on energy simulations. Simulated site EUI for the adopted design was compared with that for a second, less-creative, code-compliant design called the baseline

\footnotetext{
${ }^{4}$ For other countries alternate building energy survey data are used to determine baseline EUI.
}

design. Presumably the baseline design was projected to use more energy than the adopted design. EAc1 points were awarded based on the percentage savings reflected in these two simulated site EUI.

The first flaw with the Harvard approach is the assumption that LEED buildings achieve the site energy savings reflected in their design simulations. The use of design simulations to project environmental savings for LEED buildings was employed by Kats in 2003 before measured energy use data were available for many LEED-certified buildings [32].

Since 2002 numerous studies have found a wide disparity in the design team's energy projections for buildings and their measured post-occupancy energy use [2-16]. This phenomenon has been dubbed the "building energy performance gap [5, 9-15]." While discrepancies are found in both directions [16], the predominant trend is that measured energy use exceeds that projected during design $[5,6,7,12,13]$.

The second flaw with the Harvard methodology is the assumption that any site energy savings is achieved uniformly in all building fuels. This assumption is inconsistent with a large body of evidence which shows that LEED buildings use more, not less, electric energy than other buildings.

We are aware of 12 peer-reviewed studies published since 2008 that have specifically looked at the measured energy use of LEED-certified buildings as compared with other, similar buildings [16-27]. Key aspects of these studies are summarized in Table 1 . These summaries cannot capture the complexity of each study and interested readers are encouraged to consult the original references for details.

The first such study, conducted by the New Building's Institute (NBI) in 2008 and funded by the USGBC, concluded that LEED buildings were achieving 25-30\% (site) energy savings, consistent with their design projections [16]. This study, one of only three cited by the Harvard group, was highly criticized for its methodology and conclusions [17, 3335]. Subsequent analysis of the NBI data demonstrated that LEED buildings were achieving only half as much site energy savings as found by NBI, and more importantly, achieved no savings in source energy [17]. The explanation of this is that LEED buildings, on average, were using less natural gas and other non-electric fuels on site, but at the same time, were using more electric energy. The off-site energy losses associated with the increased on-site electric use was nullifying the on-site savings for the other fuels.

This critique [17] of the NBI study was not cited by the Harvard group, but they did cite the next two papers listed in Table 1, the first by Newsham et al. [18]. and the other by Scofield [19]. These two papers each offer further analysis of the NBI data [16]. The Harvard group states that Newsham et al. [18]. find that LEED buildings save 18$39 \%$ energy while Scofield [19] "found the energy savings 


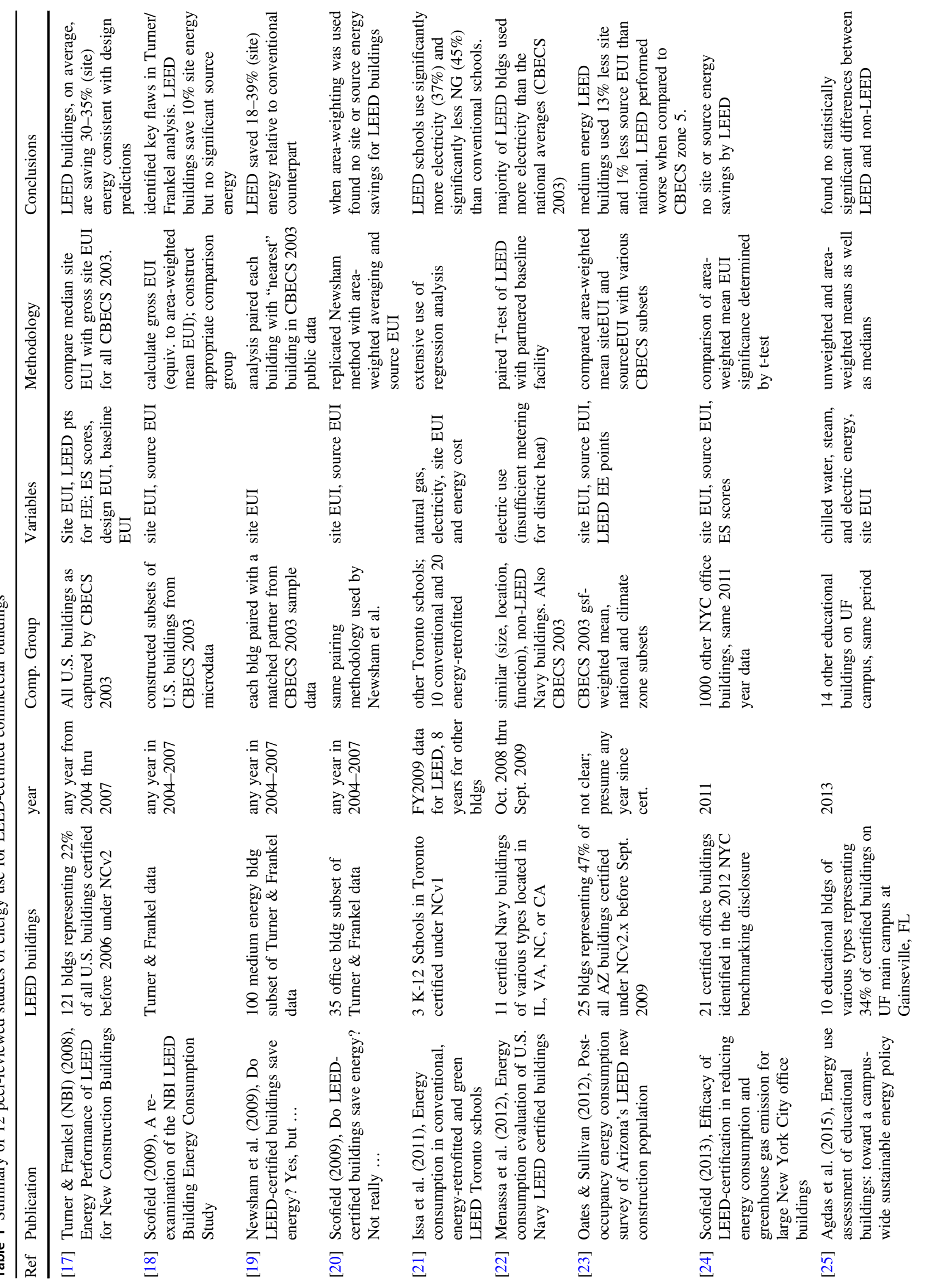




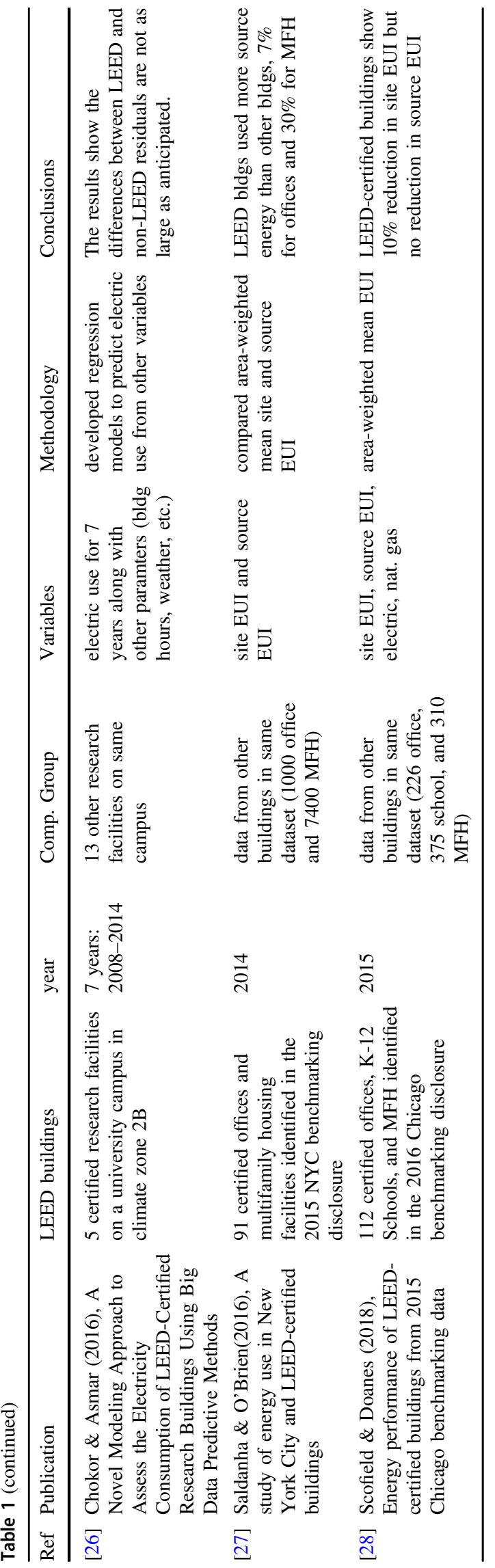

to be closer to $17 \%$." They go on to conclude, "In these studies, there remain wide discrepancies between the design and actual energy performance at the individual building level; however, as a whole, green buildings outperform conventional buildings [1]."

This conclusion, however, is not consistent with the picture that collectively emerges from these four papers [16-19]. Newsham's paper is entitled, "Do LEED-certified buildings save energy? Yes, but..." Scofield's paper is entitled, "Do LEED-certified buildings save energy? Not really..." Newsham's paper [18] provided an analysis of the NBI LEED building data [16] using an innovative approach in which each LEED building was paired with a similar building in the CBECS 2003 survey [31]. Newsham et al. confirmed but clarified the site energy savings found by Turner \& Frankel [16]. Scofield [19] recognized that Newsham's analysis relied upon the same, non-physical averaging method employed by Turner \& Frankel. ${ }^{5}$ Scofield replicated Newsham's analysis for just one building subset (35 offices) demonstrating that, with proper averaging, Newsham's methodology obtained neither site energy nor source energy savings for LEED buildings relative to their CBECS counterparts [19]. Scofield did not find $17 \%$ energy savings for LEED buildings. ${ }^{6}$

At least eight peer-reviewed studies since 2009 have examined the energy use of LEED buildings [20-27]. Those that specifically considered source energy found that LEEDcertified buildings demonstrated no source energy savings relative to other similar buildings [23, 26, 27]. Other studies did not consider source energy but found that LEED buildings did not achieve anticipated (site) energy savings $[20,22,24,25]$ and used more electric energy than did other buildings [20].

In short, building energy performance studies in the literature do not support the Harvard group's assumption that LEED-certified buildings use less primary (or source) energy than do other buildings or that site energy savings achieved by LEED buildings correspond to reduced use of all fuels.

The above two criticisms apply to 16000 of the LEEDcertified buildings included in the Harvard study. What about the remaining 4000 buildings?

The vast majority of the remaining 4000 LEED buildings (45\% of the 335 million $\mathrm{m}^{2}$ ) were certified under some version of the Existing Buildings (EB) LEED system. EAc1

\footnotetext{
5 The EUI for a collection of $\mathrm{N}$ buildings is not the average of their individual EUI. Instead it is equal to the total energy divided by the total floor area, equivalent to the area-weighted average of the individual EUI.

${ }^{6}$ This figure was lifted out of context from a reference to Scofield's earlier paper [17] in which it was found that LEED offices demonstrated $17 \%$ site energy savings but zero source energy savings relative to CBECS 2003 offices.
} 
Table 22015 data for three Chicago LEED buildings certified before 2007

\begin{tabular}{lllllllll}
\hline & & \multicolumn{3}{c}{ EUI $\left(\mathrm{MJ} / \mathrm{m}^{2}\right)$} & \multicolumn{3}{c}{ GHG $\left(\mathrm{m}\right.$-tonne $\left.\mathrm{CO}_{2}\right)$} \\
\hline ChID & LEEDID & A $\left(\mathrm{m}^{2}\right)$ & Elec. & n-Elec. & Site & actual & baseline & Savings? \\
103696 & 10001847 & 116053 & 791 & 0 & 791 & 16089 & 13552 & 3795 \\
101718 & 10001300 & 145662 & 721 & 13 & 734 & 18510 & 17009 & 4763 \\
120083 & 10001914 & 12926 & 624 & 181 & 804 & 1531 & 1509 & 423 \\
baseline & & & 529 & 477 & 1006 & & & \\
\hline
\end{tabular}

indices for these buildings are connected with the annual source EUI achieved in a year of building performance; they are neither based on site energy savings nor energy simulations. Where applicable, EAc1 points are related to the building's Energy Star score [36]. For building types that are ineligible for Energy Star scores other benchmarking methods are used to determine EAc1-but still connected to source EUI, not site EUI. The Harvard methodology for determining energy efficiency of these LEED buildings is therefore not applicable. Nowhere in their paper do they discuss a different method for handling such buildings.

Here the EAc1 index cannot be translated into site energy savings, either measured or projected. The methodology employed by the Harvard group for determining fuel savings in these cases is not only inconsistent with building performance data (as described above) but does not even apply to these buildings.

Moreover, Scofield's research has shown that the EPA's building Energy Star benchmarking scores are built on highly suspect science and, for most building types, are not reproducible [37-39]. Source energy savings inferred from Energy Star scores rely on the EPA's methodology for adjusting for external operational parameters, and this methodology has been shown to be highly flawed [39].

Now consider the Harvard group's methodology for calculating the energy savings from LEED buildings certified before 2007. While the number of such buildings is relatively small (580) their cumulative projected fuel savings is substantial because they were certified so long ago. The Harvard group assumes that all such buildings, for every year following certification, have a site EUI equal to $69 \mathrm{kBtu} / \mathrm{ft}^{2}\left(780 \mathrm{MJ} / \mathrm{m}^{2}\right)$, the median site EUI found for 121 LEED buildings in the 2008 NBI study [16]. One of the key criticisms of the NBI study was its "apples-to-oranges" approach of comparing the median LEED site EUI to gross (site) EUI for the entire U.S. commercial building stock $[17,33]$. Here the Harvard group adopts a similar approach.

Perhaps the more serious problem with their method for calculating energy savings for these early LEED buildings, however, is inherently similar to one already discussed - that a reduction in site EUI is not uniformly translated into savings in all fuels.

The problem for both newer and older (pre-2007) buildings is readily illustrated by looking at actual building energy use data. Table 2 provides relevant data for three Chicago LEED buildings that were certified prior to 2007. 2015 fuel usage data for these buildings were found in the Chicago 2016 public energy benchmarking disclosure [27, 40]. ${ }^{7}$ Table 2 lists the Chicago benchmarking building ID, LEED project ID, floor area (A), and 2015 electric, nonelectric and site EUI. The last three columns contain calculated greenhouse gas emission associated with the actual building energy use (actual), the baseline building (baseline), and the Harvard group's estimated GHG savings. The last row of Table 2 does not represent a building but, instead, contains the gross electric, non-electric, and site EUI for all buildings in census division 3 as reported in CBECS 2012 [31]. These numbers are used to determine the energy use and GHG emission of the baseline buildings. ${ }^{8}$

For all three LEED buildings we see that their actual 2015 site EUI are not significantly different from the 780 $\mathrm{MJ} / \mathrm{m}^{2}$ value assumed by the Harvard group. For these three LEED buildings the non-electric energy comes from natural gas. The GHG emission associated with the natural gas consumption does not change with time or location and is readily calculated. The GHG emission associated with the electric energy depends on the carbon content of the regional electric supply and changes with time. The Harvard group utilizes the EPA's e-grid methodology to determine the pollutants (including $\mathrm{CO}_{2}$ ) associated with electric energy [41]. Here we did the same by using the EPA's Energy Star Target Finder calculator, entering for each building its zip code, floor area, and 2015 actual fuel usage [42]. For the first building (100\% electric) Target Finder calculates GHG emission of 16089 metric tonnes $\mathrm{CO}_{2}$. GHG emissions for the other two buildings are calculated similarly and are shown in Table 2 (actual). Note that the site energy for each of the three LEED buildings is heavily dominated by electric energy.

The gross electric, non-electric, and site EUI for all commercial buildings in the 2012 CBECS census division 3

\footnotetext{
${ }^{7}$ These three were the only LEED buildings that were identified in the Chicago benchmarking data that were certified before 2007 .

8 These statistics are calculated from CBECS 2012 public microdata by extracting 900 samples for census division 3 (CENDIV =3) and calculating for these samples the total floor area (SQFT), total major fuels (MFBTU), and total electric energy (ELBTU). Non-electric energy is the difference between total major fuels and total electric.
} 
(east north central) are shown in the last row of Table 2 [31]. These are the energy intensities assumed for the baseline buildings. Buildings in this census division have roughly equal amounts of electric and non-electric site energy. For each of the LEED buildings the baseline building is assumed to have these electric and non-electric intensities. This assumed fuel usage was inputted into Target Finder to estimate the GHG emission for the three baseline buildings and is listed in Table 2 (baseline). Table 2 shows that, for each LEED building, the actual GHG for 2015 exceeds that projected for its corresponding baseline building.

The Harvard methodology, however, assumes that the $780 \mathrm{MJ} / \mathrm{m}^{2}$ site EUI for the LEED-certified building corresponds to the fuel mix found for the baseline building. The $28 \%$ reduction in site energy then corresponds to a $28 \%$ reduction in GHG emission of the baseline building. The last column of Table 2 gives GHG emissions savings calculated using the Harvard methodology for each LEED building. Whereas all three of these LEED buildings in 2015 actually produced more GHG emission than their baseline buildings, the Harvard methodology calculates the opposite.

These results are illustrated in Fig. 1 which shows the 2015 GHG savings for each building as calculated by the Harvard group (green positive bars) compared with the actual savings in GHG emission over baseline achieved by these buildings in 2015 (red negative bars). The Harvard methodology gets the sign wrong. These three LEED buildings in 2015 are responsible for more GHG emission than their baseline buildings.

It should be noted that the first Chicago building in Table 2 was certified again in 2010, then a third time in 2015, both under the LEED EBv.2 system. The second building was certified a second time in 2014 also under the EBv.2 system. These three buildings are associated with six

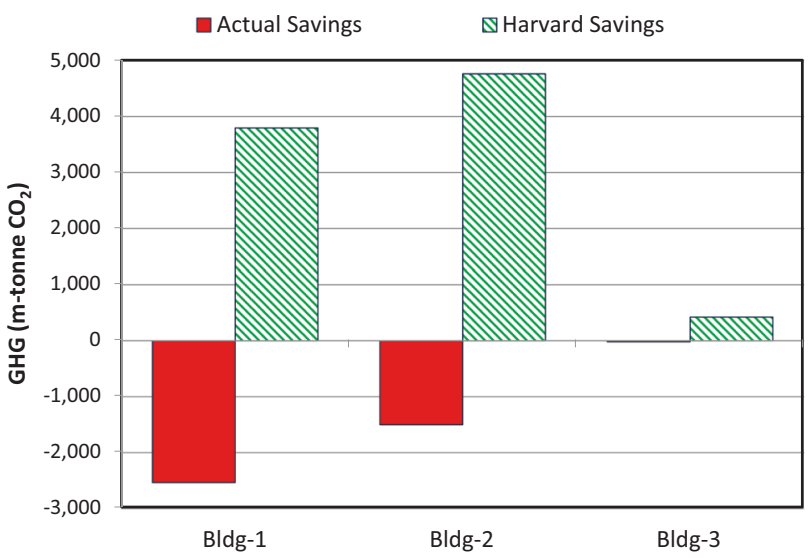

Fig. 1 GHG savings calculated using the Harvard methodololgy (green cross-hatched) and the actual GHG savings (negative in red) achieved by three LEED-certified buildings in Chicago for 2015. Harvard methodology gets the sign wrong-LEED buildings produce more GHG emission than baseline different LEED projects in the LEED project database. The Harvard group does not indicate how they handle multiple listings of a single building or even if they identify them. Indeed, the fact that we calculate the same 335 million $\mathrm{m}^{2}$ of LEED-certified floor area as they do from the LEED project database, without eliminating duplicate buildings, suggests they treat these as six separate buildings and calculate their cumulative environmental benefit using their methodology for each. If indeed the case, this error further exaggerates the environmental co-benefits of LEEDcertified buildings.

A skeptical reader might wonder if the above results for just three LEED buildings are representative of other Chicago LEED buildings. The answer is yes, readily demonstrated by applying similar analysis to the 134 LEED certified buildings $\left(10.2\right.$ million $\left.\mathrm{m}^{2}\right)$ identified in the 2015 Chicago benchmarking [27]. The measured energy use of these buildings for 2015 yields a gross site EUI of 84.8 $\mathrm{kBtu} / \mathrm{sf}\left(962 \mathrm{MJ} / \mathrm{m}^{2}\right)$, about $5 \%$ lower than the Harvard baseline for this census division (see Table 2). But because of their relatively higher electric use the GHG emissions associated with these LEED buildings for 2015 were 13\% higher than the Harvard baseline. That means for this single year these LEED buildings were responsible for $150000 \mathrm{~m}$ tonne more $\mathrm{CO}_{2}$ emission than the baseline buildings. We are not able to implement the Harvard methodology to calculate the projected GHG savings for these LEED buildings as the majority were certified with EB systems and, in addition, credible $\mathrm{EBc} 1$ indices for 45 of these buildings are not posted on the GBIG web site. No matter, the Harvard methodology, however implemented, will project GHG savings for these buildings which is the opposite of what their measured energy use demonstrate.

Above we have considered only U.S. buildings and, in our example, only looked at the Harvard group's method for calculating reduced carbon emission. The principle illustrated, however, applies to other pollutants and environmental impacts as well as buildings in the other five countries, though the details for finding the baseline energy use differ. The implied environmental co-benefits of LEED buildings are all tied to the estimated fuel savings associated with the assumed energy efficiency of these LEED buildings. The calculation we have shown for GHG emissions associated with just three Chicago LEED buildings clearly illustrates the flaws and can be replicated for other LEED buildings for which energy use data are available and for other pollutants.

\section{Discussion}

The title of the Harvard group's paper, "Energy savings, emissions reductions, and health co-benefits of the green 
building movement" suggests that the results presented generally apply to green buildings [1]. This is clearly not the case inasmuch as the analysis is restricted to LEED-certified commercial buildings-important in the United States, but a minority component of the global green-building movement.

Several inconsistencies emerged as we attempted to replicate the Harvard group's methodology for calculating the fuel savings for LEED-certified buildings. First, they claim that, "as of 2016, over 90500 commercial buildings ... have achieved LEED certification [1]." This statement is not supported by the reference they cite [43] nor have we been able to replicate this figure in our own query to the USGBC's LEED project database [29]. Our query returned 25435 such projects, 22146 if you exclude confidential buildings. ${ }^{9}$

A second problem arose when we sought design energy efficiency information from the GBIG web site for the LEED buildings in this study. The Harvard group states that energy efficiency data for each LEED building certified after 2006 is posted on the GBIG web site. This does not seem to be the case. We have data-mined the GBIG web site attempting to retrieve EA and EAc1 indices for all of the 23,000 confidential and non-confidential LEED projects (as described earlier) certified from 2000 to 2016 in the six relevant countries. EA indices were obtained for 17853 projects. Of these, credible EAc1 indices (LEED points awarded for energy efficiency) were returned for only 8788 projects, those certified under LEED v2009. ${ }^{10}$ The majority of these projects, in both number and floor area, were certified under EB O\&M for which the Harvard methodology for determining energy savings does not apply. The minority of EAc1 parameters retrieved for which the Harvard methodology applies represent just $24 \%$ of the 335 million $\mathrm{m}^{2}$ floor area of LEED buildings in this study. How then does the Harvard group determine the design energy efficiency for the remaining LEED projects representing $76 \%$ of the 335 million $\mathrm{m}^{2}$ gross floor area in their study? It should be noted that the LEED projects for which credible EAc1 indices are not posted correspond to older projects which contribute the most years of "savings" to their calculations.

The greening of buildings has become a cornerstone of most strategic plans for reducing global greenhouse gas emission. It is widely assumed, as expressed in the abstract of the Harvard paper, that green buildings save energy. Entire industries have emerged to promote green buildings

\footnotetext{
${ }^{9}$ Our query returned all projects certified before $1 / 1 / 2017$, excluding Homes, New Development (ND) and Commercial Interior (CI) LEED systems.

${ }^{10}$ For all other projects EAc1 values were listed as 0 or 1, values that were inconsistent with the total number of Energy and Atmosphere points (EA) posted for the same project.
}

including the USGBC's LEED certification, the U.S. EPA's Energy Star building certification program, BREEAM (Building Research Establishment Environmental Assessment Method), and Green Globes. Governments and other institutions have mandated that new buildings or major renovations achieve green building certification at some level through one or more of these programs. Billions of dollars are spent on these efforts annually [44].

Yet for all this effort there is relatively little evidence that green buildings actually save primary energy. In the United States, the LEED program is the most widely adopted green building certification program. Table 1 summarized the peer-reviewed studies of energy use by LEED buildings. Combined, these 12 studies provide data for, at most, 400 buildings, just $1.7 \%$ of the estimated 23000 U.S. commercial buildings certified before January 1, 2018 in one of the LEED systems that address whole-building energy use. This very small window into LEED building energy performance indicates they are not, on average, saving primary energy.

Many of the LEED building studies in Table 1 unavoidably suffer from selection bias as data are obtained voluntarily from cooperative building owners. The results of such studies may not be representative of the many buildings whose owners did not participate in the study. In the U.S. there is great hesitation to disclose confidential building energy data. In the case of LEED-certified buildings, owners have already reaped the positive marketing benefits associated with LEED certification and have much to lose should their data show poor energy performance that undermines this green publicity.

The other problem with many of the studies listed in Table 1 is the relevance of the baseline energy data to which the LEED data are being compared. In some cases the comparison data are for different years, different climate zones, and even different building types. It is useful to compare the 2012 EUI of an Arizona office building with the gross EUI for all U.S. office buildings in 2003, but the comparison has limited value. Furthermore, buildings are not stagnant and their energy consumption varies year to year for a host of reasons including weather, operating parameters, and ongoing upgrades. A single, 12-mos snapshot of a building's EUI does not characterize its energy consumption year after year any more than a single financial disclosure captures the long term profitability of a company [45].

Municipal energy benchmarking disclosure laws are providing new opportunities to address these questions. In collaboration with the Institute for Market Transformation (IMT) [46], more than 20 U.S. municipalities have passed ordinances requiring annual energy and water consumption data be reported to the municipality for large commercial buildings. In many cases these data are being made public. Over time these public disclosures will provide energy data 
for sequential years for LEED buildings and for other similar buildings to which they may be compared. Such benchmarking data were the basis for some of the more recent studies listed in Table 1 that compared the energy use of LEED-certified offices [23, 26] and multifamily housing [26] in NYC and offices, multifamily housing, and K-12 Schools in Chicago [27] with data from similar conventional buildings for the same location and time periods. In coming years these studies may be expanded to include buildings from many other U.S. cities. Maybe in 5 years or so this path will provide data for as many as 1000 LEED certified buildings with, in many cases, consecutive years of data.

There exists a better way for understanding the energy performance of LEED-certified buildings utilizing energy consumption data already gathered by the USGBC. With the adoption of LEED version 2009 (i.e., v3) the USGBC has required that all certified buildings supply 5 years of energy use data to the USGBC following certification. The first such buildings were certified in November 2009 and, as of January 1, 2017, there were 9890 U.S. commercial buildings certified under LEED v2009 systems that address whole building energy use. By now the USGBC should have collected annual energy use for all of these buildings, and in many cases, would have collected data for multiple years. ${ }^{11}$ The USGBC has never published a comprehensive study of these data nor made these data available to independent researchers for analysis.

The Harvard group has established a reasonable methodology for determining the baseline energy (and fuel use) for these buildings. Using measured energy performance for LEED buildings would yield credible fuel savings to be inputted into the Harvard Co-BE Calculator. The resulting environmental co-benefits may be positive or negative, but either way, these would be important results to have for making future energy policy and LEED decisions. One of the Harvard authors (Bernstein) has served on the board of the USGBC. Perhaps this connection might enable them to gain access to these data to produce a very useful and substantive analysis.

\section{Summary and conclusions}

McNaughton et al. calculate significant environmental benefits for 20000 buildings in six countries that were LEED-certified from 2000 to 2016. These calculated benefits are predicated on an assumed reduction in fuel usage by these buildings as compared with conventional buildings in the same geographic regions. Specifically, McNaughton

\footnotetext{
11 The LEED project database shows that 99 of these buildings were certified before 2011 .
}

et al. assume that each LEED building achieves the percentage energy savings projected by its design team and that these LEED buildings, on average, have the same fuel mix as other buildings in the same geographic region.

Here we have shown that both of these assumptions are inconsistent with the body of evidence published in the literature for LEED buildings over the last decade. Buildings in general, and LEED-certified buildings in particular, do not, on average, achieve the energy savings projected by their design teams. Furthermore, various studies have found that LEEDcertified buildings use relatively more electricity than other buildings and demonstrate no source energy savings.

Accordingly, the environmental benefits of LEED-certified buildings that McNaughton et al. calculate are no more valid than the above assumptions on which they are based.

Here we have also pointed out some important inconsistencies in the methodology that McNaughton et al. employ for determining the design energy efficiency for each LEED building.

Finally, we suggest that McNaughton et al. repeat their calculation utilizing energy consumption data already collected by the USGBC for thousands of buildings certified under LEED v2009. Replacing the projected energy savings in their calculation with real, energy consumption data for thousands of LEED buildings would provide a credible basis for truly assessing the environmental co-benefits associated with LEED building energy use.

Acknowledgements The authors thank Dr. James E. Woods for his substantive suggestions and Chana Scofield for editorial support.

\section{Compliance with ethical standards}

Conflict of interest The authors declare that they have no conflict of interest.

\section{References}

1. MacNaughton $\mathrm{P}$, Cao X, Buonocore J, Cedeno-Laurant J, Sprengle J, Bernstein A, et al. Energy savings, emission reductions, and health co-benefits of the green building movement. J Exposure Sci Environ Epidemiol. 2018;28:307-18.

2. Scofield JH. "Early energy performance for a green academic building,". ASHRAE Trans. 2002;108:1214-30.

3. Johnson J. Is what they want what they get? Examining field evidence for links between design intent and as-built energy performance of commercial buildings. Proceedings of the 2002 ACEEE Summer Study on Energy Efficiency in Buildings, vol. 4, 161-70 (American Council for an Energy-Efficient Economy, Washington, DC, 2002).

4. Barrientos Sacari JL, Bhattacharjee U, Martinez T, Duffy JJ. Green buildings in Massachusetts: comparison between actual and predicted energy performance. Solar 2007 Conference Proceedings (Cleveland, OH, July 9-13, 2007).

5. Carbon Trust. Closing the gap: Lessons learned on realizing the potential of low carbon building design. London, UK. 2011. 
https://www.carbontrust.com/media/81361/ctg047-closing-the-ga p-low-carbon-building-design.pdf

6. Menezes AC, Cripps A, Bouchlaghem D, Buswell R. Predicted vs. actual energy performance of non-domestic buildings: using post-occupancy evaluation data to reduce the performance gap. Appl Energy. 2012;97:355-464.

7. Bartlett K, Brown C, Chu A-M, Ebrahimi G, Gorgolewski M, Hodgson M, et al. Do our green buildings perform as intended? Proc. SB14 (Barcelona, 2014). http://iisbecanada.ca/umedia/cms_ files/Conference_Paper_1.pdf

8. de Wild P.. The gap between predicted and measured energy performance of buildings: a framework for investigation. Autom Constr. 2014;41:40-49.

9. Fedoruk LE, Cole RJ, Robinson JB, Cayuela A. (2015). Learning from failure: understanding the anticipated-achieved building energy performance gap. Build Res Inf. 2015;43:750-63.

10. Calì D, Osterhage T, Streblow R, Müller D. "Energy performance gap in refurbished German dwellings: lesson learned from a field test. Energy Build. 2016;127:1146-58. https://doi.org/10.1016/j. enbuild.2016.05.020

11. van Dronkelaar C, Dowson M, Burman E, Spataru C, Mumovic D. A review of the energy performance gap and its underlying causes in non-domestic buildings,". Front Mech Eng. 2016;1:17

12. Innovate UK. Building performance evaluation programme: findings from non-domestic projects. 2016. https://assets. publishing.service.gov.uk/government/uploads/system/uploads/a ttachment_data/file/497758/Domestic_Building_Performance_ full_report_2016.pdf

13. Herrando M, Cambra D, Navarro M, de la Cruz L, Millán G, Zabalza I. Energy performance certification of faculty buildings in Spain: the gap between estimated and real energy consumption,". Energy Convers Manag. 2016;125:141-53.

14. Iman S, Coley DA, Walker I. The building performance gap: are modelers literate?". J Build Serv Res Technol. 2017;38:351-75. https://doi.org/10.1177/0143624416684641.

15. Conniff R. "Why don't green buildings live up to the hype on energy efficiency?" Yale Environment 360: New Haven, CT. 2017. http://e360.yale.edu/features/why-dont-green-buildingslive-up-to-hype-on-energy-efficiency

16. Turner $\mathrm{C}$ and Frankel M. Energy performance of LEED for new construction buildings - final report. New Buildings Institute, White Salmon, WA. 2008. http://newbuildings.org/resource/ energy-performance-leed-new-construction-buildings/

17. Scofield JH. A re-examination of the NBI LEED Building Energy Consumption Study. Proceedings of the International Energy Program Evaluation Conference (IEPEC) (Portland, OR, August 12-14, 2009).

18. Newsham G, Mancini S, Birt Benjamin J. Do LEED-certified buildings save energy? Yes, but...,". Energy Build. 2009;41:897905.

19. Scofield JH. “"Do LEED-certified buildings save energy? Not really...,". Energy Build. 2009;41:1386-90.

20. Menassa C. et al. "Energy consumption evaluation of U.S. Navy LEED certified buildings,”. J Perform Constr Facil. 2012;25:46-53.

21. Issa MH, Attalla M, Rankin JH, Christian J. Energy consumption in conventional, energy-retrofitted and green LEED Toronto schools. Constr Manag Econ. 2011;29:383-395.

22. Oates D, Sullivan KT. "Post-occupancy energy consumption survey of Arizona's LEED new construction population,”. J Constr Eng Manag. 2012;138:742-50.

23. Scofield JH. "Efficacy of LEED-certification in reducing energy consumption and greenhouse gas emission for large New York City office buildings,". Energy Build. 2013;67:517-24.
24. Agdas D, Srinivasan RS, Frost K, Masters FJ. Energy use assessment of educational buildings: toward a campus-wide sustainable energy policy,". Sustain Cities Soc. 2015;17: $15-21$.

25. Chokor A, El Asmar M. A novel modeling approach to assess the electricity consumption of LEED-certified research buildings using big data predictive methods. Construction Research Congress 2016: Old and New Construction Technologies Converge in Historic San Juan-Proceedings of the 2016 Construction Research Congress, CRC. 1040-9 (American Society of Civil Engineers (ASCE), 2016).

26. Saldanha CM, O'Brien SM. A study of energy use in New York City and LEED-certified buildings. Building Performance Modeling Conference 377-384 (ASHRAE and IBPSA-USA SimBuild, Salt Lake City, UT, August 8-12, 2016).

27. Scofield JH, Doanes J. Energy performance of LEED-certified buildings from 2015 Chicago benchmarking data. Energy Build. 2018;174:402-13.https://doi.org/10.1016/j.enbuild.2018.06.019.

28. EPA. Source Energy. Energy Star Portfolio Manager Technical Reference. 2018. https://portfoliomanager.energystar.gov/pdf/ reference/Source\%20Energy.pdf

29. The LEED project database, https://www.usgbc.org/projects, downloaded on 2017-12-26.

30. http://www.gbig.org

31. https://www.eia.gov/consumption/commercial/

32. Kats G. The costs and financial benefits of green buildings. A Report to California's Sustainable Building Task Force. 2003. http://evanmills.lbl.gov/pubs/pdf/green_buildings.pdf (downloaded 2018-02-24).

33. Gifford H. A better way to rate green buildings. 2008. http://www. solaripedia.com/files/223.pdf (downloaded 2018-06-06).

34. Lstiburek JW. Why green can be wash. ASHRAE J. 2008;28-36.

35. Richter B, Goldston D, Crabtree G, Glicksman L, Goldstein D, Greene D, et al. Energy future: think efficiency (American Physical Society, College Park, MD, 2008). http://www.aps.org/ energyefficiencyreport/index.cfm

36. https://www.energystar.gov/buildings/about-us/how-can-we-helpyou/benchmark-energy-use/benchmarking

37. Scofield JH. ENERGY STAR building benchmarking scoresgood idea, bad science ACEEE Summer Study on Buildings, Pacific Grove, CA, August 17-22, 2014. http://aceee.org/files/ proceedings/2014/data/papers/3-725.pdf

38. Scofield JH, Richman G. Results of validation tests applied to seven ENERGY STAR building models. 2015 International Energy Program Evaluation Conference (Long Beach, CA, August 11-13, 2015). https://www.iepec.org/wp-content/uploads/ 2015/papers/158.pdf

39. Scofield JH. Building Energy Star Scores: Good Idea, Bad Science (CreateSpace Independent Publishing Platform, 2016).

40. https://www.cityofchicago.org/city/en/depts/mayor/supp_info/ chicago-energy-benchmarking/Chicago_Energy_Benchmarking_ Reports_Data.html

41. https://www.epa.gov/energy/egrid

42. https://portfoliomanager.energystar.gov/pm/targetFinder

43. USGBC. USGBC statistics. 2016; https://www.usgbc.org/articles/ usgbc-statistics

44. Green building economic impact study. prepared for the U.S. Green Building Council by Booz Allen Hamilton, September 2015. http://go.usgbc.org/2015-economic-impact-report.html

45. Scofield JH. A Paler Shade of Green. HPAC Engineering, 26-31 (January 10, 2013). https://www.hpac.com/air-conditioning/adamjoseph-lewis-center-paler-shade-green

46. https://www.imt.org/ 